\title{
Discurso, estrategias e interacciones de Vox en su cuenta oficial de Instagram en las elecciones del 28-A. Derecha radical $y$ redes sociales
}

\author{
Vox political party discourse, strategies and interactions in its \\ Instagram official account in the 28-A elections. Radical right and \\ Social Networks
}

Eva Aladro Vico. Universidad Complutense de Madrid. España.

ealadro@ucm.es

[CV] 1 G

Paula Requeijo Rey. Universidad Complutense de Madrid. España.

p.requeijo@ucm.es

$[\underline{\mathrm{CV}}]$ O G

Cómo citar este artículo / Referencia normalizada

Aladro Vico, E. y Requeijo Rey, P. (2020). Discurso, estrategias e interacciones de Vox en su cuenta oficial de Instagram en las elecciones del 28-A. Derecha radical y redes sociales. Revista Latina de Comunicación Social, (77), 203-229. https:/www.doi.org/10.4185/RLCS-2020-1455

\begin{abstract}
RESUMEN
Introducción: Investigamos el uso de la cuenta oficial de Vox en Instagram en los dos meses previos a las elecciones del 28-A. Objetivos y metodología: Se revisan diversos textos para situar a la formación ideológicamente, identificar los ejes de su discurso y el papel de Instagram en su comunicación. Se seleccionan los mensajes de su cuenta en el período de estudio, obteniendo una muestra de 81 publicaciones. Mediante validación, se determinan los ejes del discurso, estrategias de comunicación e interacción. Se profundiza en el análisis de las 20 publicaciones con mayores niveles de interacción. Resultados: Normativismo, nativismo, y mentalidad cerrada grupal dominan las estrategias y narrativas identitarias de Vox, en cadenas metafóricas y sinécdoques. Conclusiones: Vox se presenta como un movimiento de resistencia civil que se adapta al código de los jóvenes. Predominan las estrategias de polarización política, el nativismo, el culto a la norma, el hiperliderazgo y el lenguaje simplificador de carga.
\end{abstract}

PALABRAS CLAVE: comunicación política; elecciones generales 28-A; Instagram; Vox; discurso.

\begin{abstract}
Introduction: We investigate how Vox has used its official Instagram account during the two previous months to the 28-A elections. Objectives and methodology: Various texts are reviewed in order to place the political group ideologically, identify its discourse axes and the role of Instagram in its communication. Messages in the official account during the studied period are selected, obtaining a sample of 81 publications. Through a validation table, communication strategies, discourse axes and interaction are determined. We deepen into the analysis of the 20 publications
\end{abstract}


with the highest interaction levels. Results: Cult of law, nativism and closed groupthinking are the main strategies and narratives of Vox, using metaphors and sinecdoques in clusters. Conclusions: Vox presents itself as a civil resistance movement that adapts to the youth code. Predominant communication strategies favor political polarization, nativism, law and order cult, with a hyperleadership and a simplifying language.

KEYWORDS: political communication; 28-A general elections; Instagram; Vox political party; discourse.

\section{CONTENIDOS}

1. Introducción. 2. Metodología. 3. Marco teórico. 3.1. Derecha radical. 3.2. Contexto sociocomunicativo, mentalidad cerrada y sociedad digital. 3.3. Primera aproximación a los ejes del discurso de Vox. 3.4. Instagram y Vox. 4. Resultados. 4.1. Tipo de publicaciones y temas. 4.2. Enunciadores en el texto. 4.3. Publicaciones con mayor nivel de interacción. 4.4. Funciones del lenguaje, significantes clave y significados. 5. Discusión y comentario de los ejemplos más relevantes. 5.1. Ejes del discurso. 5.2. Estrategias de comunicación. 5.2.1. Creación de un enemigo interno y externo. 5.2.2. Construcción de la identidad del grupo-comunidad por medio de narrativas de pertenencia que se contraponen a los enemigos. 5.2.3. Eliminación de las diferencias dentro del grupo. 5.2.4. Normativismo: la ley y el orden como discursos dominantes. 5.2.5. Emocionalidad, agresividad y explotación del miedo. 5.2.6. Rechazo de la complejidad y lenguaje simplificador de carga. 6. Discusión. 7. Conclusiones 8. Referencias bibliográficas.

\section{Introducción}

El partido político de derecha radical Vox (del latín "voz") nace a finales de diciembre del año 2013. Se presenta en un acto en Madrid a mediados de enero de 2014. Su presidente, Santiago Abascal, estuvo afiliado al Partido Popular (PP) entre 1994 y 2013 y tuvo distintos cargos políticos como miembro de esta formación. Decidió abandonarla porque, según sus propias palabras, la dirección había "traicionado sus valores y sus ideas". Entre las razones para ese abandono, el líder indicó la posición del PP ante el terrorismo en Euskadi, y otras claves que son importantes, porque estarán presentes en el manifiesto fundacional de Vox (2014): la postura del PP frente a los nacionalismos periféricos, la ausencia de una reforma del Estado de las autonomías, la subida de los impuestos, el mantenimiento de la Ley de salud sexual y reproductiva y de interrupción voluntaria del embarazo (2010) y la pasividad frente a la corrupción dentro del partido.

Estos serán temas centrales del discurso de la formación y sus propuestas: en las medidas de su manifiesto fundacional (2014), de sus Estatutos $(2015,2019)$ y de las llamadas "100 medidas para la España Viva" (2015b, 2018). No es hasta diciembre de 2018 cuando Vox consigue representación parlamentaria por primera vez, logrando en las elecciones andaluzas el 10,97\% del voto, y obteniendo 12 escaños (Gil Grande, 2018a).

Una de las razones de peso del éxito de Vox es la declaración de independencia de Cataluña en octubre de 2017 y el desarrollo de distintos acontecimientos relacionados con la misma. El tema del conflicto catalán se convirtió en uno de los principales de la agenda de las elecciones andaluzas (Castro, 2018; Camacho, 2018). En el nuevo contexto, más polarizado y agitado tras la escalada de tensión, con la entrada en prisión de algunos de los líderes independentistas, el discurso contra el peligro desintegrador del nacionalismo periférico atrajo a una parte de los votantes andaluces (Gil Grande, 2018b; Araluce, 2019; Ferreira, 2019). 
El fenómeno se repite a nivel nacional en 2019 y la formación logra entrar por primera vez en el Congreso en las primeras elecciones generales, con un porcentaje de voto similar al de Andalucía (10,26\%) como quinta fuerza política (Martín Plaza, 2019a). Unos meses después, con la repetición electoral celebrada en un contexto todavía más polarizado, -con la sentencia del Tribunal Supremo que condenaba de 9 a 13 años de cárcel a nueve líderes independentistas (Rincón, 2019) y la exhumación del dictador Francisco Franco (Romero 2019)-, Vox multiplicó su éxito logrando el 15,09\% de los votos, doblando número de escaños y convirtiéndose en la tercera fuerza del Congreso (Martín Plaza, 2019b).

La prensa calificó 2014 como "el año Podemos" (Requeijo, 2018). Estableciendo una analogía y, teniendo en cuenta lo que acabamos de describir, podemos afirmar que 2019 ha sido el año Vox. Detrás de su auge, está el hecho de que algunos de los principales ejes de su discurso inicial, sobre todo el de la amenaza de los nacionalismos periféricos, conectan con fuerza con el contexto actual (Cruz, 2019) pero también hay que tener en cuenta los canales a través de los que proyectan y difunden este discurso. Si las redes sociales fueron indispensables para el éxito de Podemos, lo van a ser también para el de Vox (Viejo, 2018). Hasta el punto de que se ha convertido en el partido político que más seguidores tiene en Instagram (481.803) desbancando ampliamente a Podemos (210.967) y cuadriplicando las cifras de Ciudadanos, el Partido Popular y el PSOE (109.087, 92.163 y 86.751 seguidores respectivamente).

El triunfo de Vox en esta red social no es algo casual, sino que se debe a una minuciosa y constante estrategia detrás de la que se encuentran actores tan importantes como Steve Bannon (Ferreira, 2019; Gould, 2019; Rendueles, 2019) que asesora a sus dirigentes desde 2017 (Verdú, 2019). Se trata de un esfuerzo por conectar con los segmentos de votantes más abstencionistas y desencantados de la política convencional (Mateos y Moral, 2006; Galais, 2012; Francés y Santacreu, 2014; Benedicto et al., 2016; Camas, 2017) que ha dado, en parte, sus frutos: en las últimas elecciones generales, el partido más votado por los hombres menores de 30 años (el 19,4\% del total) es Vox, seguido de cerca por Podemos $(17,4 \%)$. Sin embargo parece que este esfuerzo sólo les ha permitido penetrar en el público joven masculino. En mujeres jóvenes menores de 30 años, las cifras de voto a Vox descienden considerablemente: sólo el 6,5\% de ellas se decantó por este partido (Carpio, 2019; Espartero, 2019). Las estrategias de masculinización del discurso (Alabao, 2018; Fernández, 2019) y la crítica al feminismo, están detrás de estos resultados.

El objetivo de esta investigación que se enmarca en el Proyecto Europeo AGLAYA: Estrategias de Innovación en Mitocrítica Cultural ${ }^{1}$ es analizar el uso comunicativo que la formación hizo de Instagram ante las elecciones generales del 28 de abril de 2019 (en adelante 28-A), las primeras a nivel nacional en las que consigue representación. Nuestro corpus de estudio, como explicaremos en el siguiente apartado, lo conforman las publicaciones de Vox en esta red social durante los dos meses previos a las elecciones. Elegimos esta red porque es aquella en la que la formación se muestra más eficaz y activa, frente a otros partidos. Nos interesa identificar los ejes de su discurso en la plataforma, las estrategias comunicativas que emplean y el nivel de interacción de los mensajes. En las veinte publicaciones con un mayor nivel analizaremos, además, cuáles son sus significantes clave y a qué significados nos remiten.

\section{Metodología}

Para alcanzar el objetivo planteado hemos seguido una serie de pasos metodológicos que quieren evolucionar en espiral, hacia los rasgos distintivos de Vox en Instagram. En primer lugar hemos

\footnotetext{
1 Esta investigación se enmarca en una mayor del Proyecto Europeo "AGLAYA: Estrategias de Innovación en Mitocrítica Cultural”, Ref: H2019/HUM-5714. , 2020-2023, de la que son miembros y Co-Ip las autoras de este artículo.
} 
desarrollado un breve estado de la cuestión sobre por qué Vox debe enmarcarse dentro de la derecha radical, los ejes de su discurso en general, para corroborar luego esos ejes y matizar la importancia que Instagram tiene en la comunicación del partido. Hemos situado el arranque de nuestra investigación en la base de investigadores y autores de diversas épocas, sobre pensamiento autoritario y mentalidad cerrada.

En segundo lugar, hemos desarrollado un análisis cuantitativo del uso que Vox ha hecho de Instagram en los dos meses previos a las elecciones generales del 28-A (desde el 28-02-2019 hasta el 28-04-2019 incluido). La justificación para ese plazo de fechas está en su coincidencia con la campaña electoral y con el despegue de las interacciones comunicativas de la formación en esta red. Hemos procesado de este conjunto total, que usamos como base muestral, los elementos significativos, ofreciendo los que nos parecen más representativos y que nos inducen a la tercera fase del análisis.

En esa tercera parte desarrollamos un análisis cualitativo de las 20 publicaciones con mayor nivel de interacción atendiendo a los ejes del discurso, las estrategias comunicativas y los niveles de interacción. Hemos comentado los ejemplos más representativos atendiendo a sus palabras, fotografías, vídeos y enlaces así como las publicaciones que presentan los mayores niveles de interacción.

Para acometer los pasos dos y tres, nos hemos servido de dos tablas de validación compuestas por una serie de variables. Estas variables identifican aspectos como el tipo de publicación (carrusel, imagen o vídeo), el tema en el que se centra, quiénes actúan como enunciadores en el texto o el nivel de interacción, que obviamos en el texto para no redundar demasiado. Hemos seleccionado las veinte publicaciones con mayores niveles de interacción, y hemos analizado las estrategias, significantes clave y significados.

\section{Marco teórico}

\subsection{Derecha radical}

Es necesario, en primer lugar, situar en qué etiqueta de ideología de derechas vamos a ubicar a Vox. Numerosos medios de comunicación, así como sus adversarios, lo catalogan como extrema derecha. El partido rechaza esta etiqueta y se define a sí mismo como "liberal conservador" en palabras de Espinosa de los Monteros, vicesecretario de Relaciones Internacionales (El Confidencial Digital, 2019). Sin embargo, hay literatura académica que ha argumentado y reflexionado sobre por qué no debe asignársele ni una ni otra etiqueta, sino que lo correcto es hablar de derecha radical.

La politóloga Pippa Norris (2005) explica que lo que caracteriza a la extrema derecha es su rechazo al sistema democrático y su apoyo al uso de la violencia para lograr fines políticos. Siguiendo a Norris y a otros autores como Cas Mudde (2007) o Jens Rydgren (2018), Ferreira (2019) subraya que, a diferencia de la extrema derecha y aunque niegue algunos de los planteamientos de la democracia liberal, la derecha radical no está en contra del sistema democrático y tampoco defiende el uso de la violencia.

Lo que la caracteriza son el nativismo y el autoritarismo, que Ferreira (2019, p. 82) define como sus "condiciones necesarias y suficientes". El nativismo es "un movimiento cuyo objetivo principal es restringir el flujo de inmigrantes para mantener el statu quo cultural, racial, religioso o político en un país, región, o ciudad". Los requisitos para que tenga éxito implican crear "un enemigo interno o externo claro y convincente", suprimir "las diferencias internas a nivel social e ideológico en el seno 
de la población "nativa" y construir "una narrativa de pertenencia categórica e incontestada" (Guia, 2016).

En el caso europeo, a diferencia del estadounidense, el nativismo posterior a la II Guerra Mundial se vincula desde sus inicios con el rechazo a los musulmanes. Estos se definen por sus "tradiciones patricarcales y religiones ortodoxas", opuestas a los valores propios del sistema democrático (Guia, 2016).

Al hablar de autoritarismo, nos referimos a "la creencia en una sociedad estrictamente ordenada, donde las infracciones a la autoridad tienen que ser severamente castigadas" (Mudde, en Ferreira, 2019). Otras características como la defensa de los valores tradicionales o el neoliberalismo pueden estar más o menos presentes en la derecha radical, pero no son determinantes como las dos anteriores. En el caso de Vox, no sólo la defensa de la ley y el orden sino también los valores tradicionales son esenciales en su discurso. Dedicaremos el próximo apartado a desarrollar desde una perspectiva socio-psicológica el porqué de esta cuestión.

Tras un análisis detallado de los principios ideológicos clave de Vox, siguiendo el método de la cadena casual, Ferreira (2019) concluye que la formación se sitúa dentro de la derecha radical. La razón está en que lo que prima en su discurso son el nativismo y el autoritarismo, aunque también propugnen los valores tradicionales. Vox no sería extrema derecha porque no apoya la violencia para alcanzar sus fines y, aunque no respeta ciertos aspectos de la democracia liberal, no la rechaza de pleno. Tampoco se puede identificar simplemente con el conservadurismo, por la importancia del nativismo en su discurso.

En la misma línea que planteaba Ferreira, el investigador Pueyo-Rubio (2019) también sitúa a Vox dentro de la derecha radical y subraya la importancia del nacionalismo político en su discurso. Un nacionalismo que, como ya hemos apuntado a través de Ferreira (2019) y detallaremos en esta investigación, va más allá y se convierte en nativismo, ya que crea un enemigo que supone una amenaza para la pervivencia de los valores del grupo.

\subsection{Contexto socio-comunicativo, mentalidad cerrada y sociedad digital}

Desde una perspectiva socio-psicológica la derecha radical conecta con el concepto de mente reaccionaria y cerrada. Hay una gran corriente de análisis que se abre con los estudios de Adorno (Adorno et al., 1950) y que actualizan autores durante todo el siglo XX y XXI, como Altemeyer (1981), y recientemente, Jost et al., (2003) que explica la mentalidad que justifica posiciones militaristas, de dogmatismo absoluto o basadas en valores normativos exagerados.

El surgimiento de movimientos de mentalidad autoritaria y dogmática es en realidad una "cognición social motivada" (Jost et al., 2003). En situaciones de incertidumbre e inseguridad, amenaza de cambios, incremento de las desigualdades y crisis económica, o en momentos de mayor turbulencia social, el pensamiento autoritario y los partidos de derecha vinculados al mismo, ofrecen compensaciones que se convierten en mayoritarias una vez que empiezan a aparecer los fenómenos de pensamiento grupal (Janis, 1972) y de sectarismo generado por el miedo a la libertad (Fromm, 1941). Este contexto coincide, precisamente, con el que favorece el nacimiento o el refuerzo del nativismo: la "crisis de confianza en la nación" motivada "por cuestiones económicas, culturales o políticas" (Guia, 2016, p. 115). Recientes investigaciones como la de Enrique Del Teso $(2018,2020)$ inciden en la idea de cómo la propaganda y estilos comunicativos de derecha radical generan identificación grupal y sus usos del lenguaje en apelación individual van encaminados al refuerzo del grupo. 
Estas estructuras pueden surgir y fortalecerse en momentos de innovación social y de cambios vertiginosos en la evolución de las comunidades, como un movimiento de reacción y de involución instintiva. Así, siguiendo de nuevo a Adorno y sus colaboradores, los reacios a los cambios e innovaciones abrazan el ideario de un líder autoritario porque ello les permite fortalecerse en sus posiciones defensivas y rechazar el crecimiento indeseado o la libertad temida (Fromm, 1941). Hay literatura muy reciente sobre esos procesos como las investigaciones de Aral, Muchnik y Sundadarajan (2009), y Aral y Walker (2015).

Algunos de los rasgos que los autores tradicionales describieron en los partidos y movimientos de derecha autoritaria a mediados del siglo XX siguen presentes hoy en partidos de extrema derecha $\mathrm{y}$ de derecha radical como Vox. Entre ellos destacamos:

- convencionalismo: culto a las normas y costumbres sociales tradicionales.

- mentalidad de servicio y obediencia a un líder, con una marcada proyección de personalidades al frente de estos movimientos.

- agresividad hacia el exterior, con una tendencia al cierre de sus redes y a la homofilia o pensamiento unánime (Rogers, 1981).

- organización interna de extremo rigor para favorecer el pensamiento grupal y la conformación de un ejército piramidal que transfiera fuerza a sus bases y autoridad a su dirigente (Janis, 1972).

- compensaciones grupales de las debilidades individuales, con transferencias de poder y estima al grupo, nación o líder, por parte de personalidades débiles o amenazadas, o bien poco socializadas (Janis, 1972).

- mentalidad cerrada o dogmática (Rokeach, 1960).

Para desarrollar nuestra investigación nos interesa particularmente la ampliación que sobre la idea de personalidad autoritaria de derechas, de etiología psicosocial, hizo Milton Rokeach relacionando el fenómeno con ciertas estrategias y circunstancias informativas y comunicativas.

Rokeach vinculó los grupos y fenómenos sociales asociados al conservadurismo extremo con cierres informacionales en los sistemas de creencias personales. Así, las personas de mentalidad cerrada experimentan la tendencia a rechazar la información contraria a sus creencias y principios. El lenguaje que consigue reforzar la mentalidad cerrada es el lenguaje del dogmatismo, de las creencias firmes en extremo, de la normatividad absoluta (Rokeach, 1960). La simplificación del lenguaje, el rechazo a la complejidad y el culto al orden sirven comunicativamente para despejar la dificultad cognitiva en un entorno de alta carga comunicacional o informativa.

A mediados del siglo XX, en los Estados Unidos, la escalada de la Guerra Fría, la modernización urbana y el avance de las estrategias de propaganda y publicidad, propiciaron el aumento de comunidades y grupos sociales muy reacios a aceptar innovaciones (Rogers, 1981). Veían con terror el avance de los medios y tecnologías modernas y tendían a buscar seguridad en el convencionalismo y el cierre a la información cosmopolita.

En nuestros días, el advenimiento de la digitalización, las diferencias económicas y geográficas y las nuevas situaciones tecnológicas, imponen unas condiciones similares para el surgimiento de la mentalidad cerrada en partidos políticos. Son lo que conocemos hoy como nuevos populismos y nuevos partidos de ideologías extremas. En nuestro caso, como ya hemos indicado, nos ocuparemos de una formación que se enmarca en la derecha radical.

Así, y si relacionamos el auge de los partidos de dogmas tradicionales absolutos, normativistas y cerrados al entorno innovador, con el marco de la sociedad digital, veremos que se está produciendo 
el cierre de mentalidad característico de situaciones de sobrecarga informativa. La búsqueda de los valores tradicionales, el convencionalismo o el culto a las normas son rasgos de un miedo a la libertad que se ha generado con la sociedad globalizada y extremadamente abierta del mundo actual.

La desagregación de los cauces tradicionales de comunicación de masas se ve sustituida por las nuevas esferas interpersonales de las redes digitales, donde la formación de mentalidades sectarias y de pensamiento grupal es mucho más fácil por su propia idiosincrasia. Podemos relacionar con claridad determinadas redes sociales actuales con las redes homofílicas tradicionales (Aladro, 2013; Valera-Ordaz, Calvo y López-García, 2018) en determinadas mecánicas e interacciones características. En las redes sociales es posible vehicular además las compensaciones y transferencias psicológicas características de los grupos homofílicos y cerrados, mediante un lenguaje y un estilo de comunicación distintivo, emocional y agresivo (Del Teso, 2020).

\subsection{Primera aproximación a los ejes de discurso de Vox}

En una primera aproximación que después desarrollaremos con más profundidad gracias al análisis del Instagram del partido, hemos identificado los ejes básicos del discurso de Vox a partir de tres tipos de textos: los documentos base elaborados por la propia formación, tres de los principales discursos que su líder, Santiago Abascal, puso en escena en el marco temporal de nuestra investigación (28 de febrero-28 de abril de 2019) y la entrevista que hizo con el presentador de TV Bertín Osborne en los días previos a la campaña electoral (6 de abril de 2019).

Entre los documentos base de Vox hemos analizado la carta al expresidente del PP Mariano a Rajoy (2013), su manifiesto fundacional (2014), sus estatutos (2015a; 2019) y las 100 medidas para la España Viva y para los municipios (2015b; 2018). Los discursos de Santiago Abascal que hemos seleccionado son el de Santander del 28 de marzo de 2019, el de Covadonga del 12 de abril de 2019 y el de cierre de campaña de la Plaza de Colón del 26 de abril de 2019.

Todos estos documentos reflejan que hay cuatro ejes que vertebran el discurso del partido que vendrían a actuar como peligros o amenazas: los nacionalismos periféricos, la inmigración musulmana, el feminismo y la izquierda. Esta última, además, representa un peligro especial ya que apoya y aglutina a los tres anteriores. Todos ellos se enmarcan dentro del nativismo ya que ponen en peligro no sólo la identidad de los españoles como grupo sino la propia continuidad del mismo. Comprobaremos posteriormente si se repiten estos temas en Instagram.

\subsection{Instagram y Vox}

Hay ya una importante literatura académica sobre el uso político de las redes sociales, tanto desde un punto de vista crítico como desde un enfoque instrumental (Aral, 2012; Filimonov, 2016; Jung et al., 2016; Zuckerman, 2017; Lovink et al., 2017); con algunos autores en España especializados en movimientos socio-políticos y redes sociales (Gallardo Paúls y Enguix Oliver, 2016; Pinazo, Nós y Agut, 2020). Se investiga también específicamente sobre Instagram y sus capacidades de persuasión y captación en diversos sectores, de la política al consumo (Eldin, 2015; Sheldon y Bryant 2016; Evans et al., 2017; Casaló, Flavian e Ibáñez, 2018). El interés actual se centra en su uso político, a partir del caso Cambridge Analytica, entre otros, y hay ya interesantes reflexiones en nuestro país (Selva-Ruiz y Caro Castaño, 2017).

Como indicamos en la introducción, Vox es el partido español con más seguidores en Instagram. En España, esta red alcanza los 15 millones de usuarios, y 5 millones son jóvenes menores de 35 años. Aunque este partido logra buenos niveles de interacción en las cuatro redes más importantes en 
nuestro país -Facebook, Twitter, YouTube e Instagram-, es en esta última donde obtiene los mejores resultados (Cea, 2019). Si atendemos al engagement (compromiso de los usuarios), sus publicaciones son de nuevo las que alcanzan los mejores niveles entre las formaciones políticas, siendo otra vez Instagram la red más importante (Cea, 2019).

Hay importantes similitudes entre el discurso de la formación que estudiamos y el de Donald Trump tanto a nivel de contenido como de forma (Pardo, 2019) en redes sociales. La razón de este hecho, y del éxito de Vox, está en asesores como Steve Bannon, exvicepresidente y fundador de Cambridge Analytica y jefe de campaña de Trump. Rafael Bardají, miembro del Comité Ejecutivo Nacional de Vox, se ha reunido varias veces con Bannon. Las estrategias empleadas van de colaborar con cuentas de perfil prescriptor, a utilizar el mismo lenguaje que los segmentos de la población a los que se dirigen, y relacionar las publicaciones con hashtags o etiquetas que son tendencia o despiertan especial interés (Cea, 2019).

\section{Resultados}

\subsection{Tipo de publicaciones y temas}

Antes de comenzar el análisis es necesario señalar que Instagram permite realizar dos tipos diferentes de publicaciones: noticias y stories. Las noticias son publicaciones permanentes en el muro de cada perfil en la red. Las stories, en cambio, son vídeos o imágenes con carácter efímero. Tienen una fecha de caducidad, desapareciendo en 24 horas, por lo que solo hemos analizado las noticias.

En total el partido publicó 81 noticias en el período de estudio (28-02-2019 al 28-04-2019) que conforman la muestra o corpus. Observamos que de las 81 publicaciones propias (noticias) la mayoría son vídeos $(78 \%)$ y el resto imágenes. En cada publicación se suele incluir un solo vídeo (46\%) o bien varios combinados (31\%). Dentro de las imágenes, hemos distinguido distintos tipos, como las fotografías, los carteles, los memes y las portadas de medios.

Las imágenes se corresponden sobre todo con fotografías (10\%). En ellas aparecen los líderes de Vox, manifestantes (Plaza de España, en Barcelona y Plaza de Colón, en Madrid) o simpatizantes (asistentes a los mítines). El objetivo, en parte, es representar la idea de que Vox tiene un amplio apoyo popular y que es un movimiento de la ciudadanía más que un partido político convencional. Es algo en lo que Abascal insiste también en la entrevistas que concede y los discursos que pone en escena.

Los carteles $(6 \%)$ informan sobre actos electorales y manifestaciones. Están pensados para llamar a la movilización de los simpatizantes.

Los memes (5\%) emplean el humor para desmotivar en relación al voto útil, comparar la fortaleza de Abascal con la debilidad del presidente del Gobierno, Pedro Sánchez, al que se representa como una mariquita, subrayar la utilidad y éxito de Vox al establecer un paralelismo entre la formación y empresas estadounidenses como Apple o Amazon, y destacar el aspecto de guerra que se libra frente a enemigos como la II República Española, el comunismo, el feminismo o el movimiento LGTBI.

Hemos tratado de especificar los temas del discurso en Instagram lo máximo posible para facilitar la discusión posterior y el comentario de los mismos. Hemos identificado un total de 18. Sin embargo, la mayoría se agrupa claramente en torno a los ejes vertebradores identificados en la primera aproximación desarrollada en el marco teórico, a partir del análisis de los textos base del partido, los discursos y entrevista de su líder. 


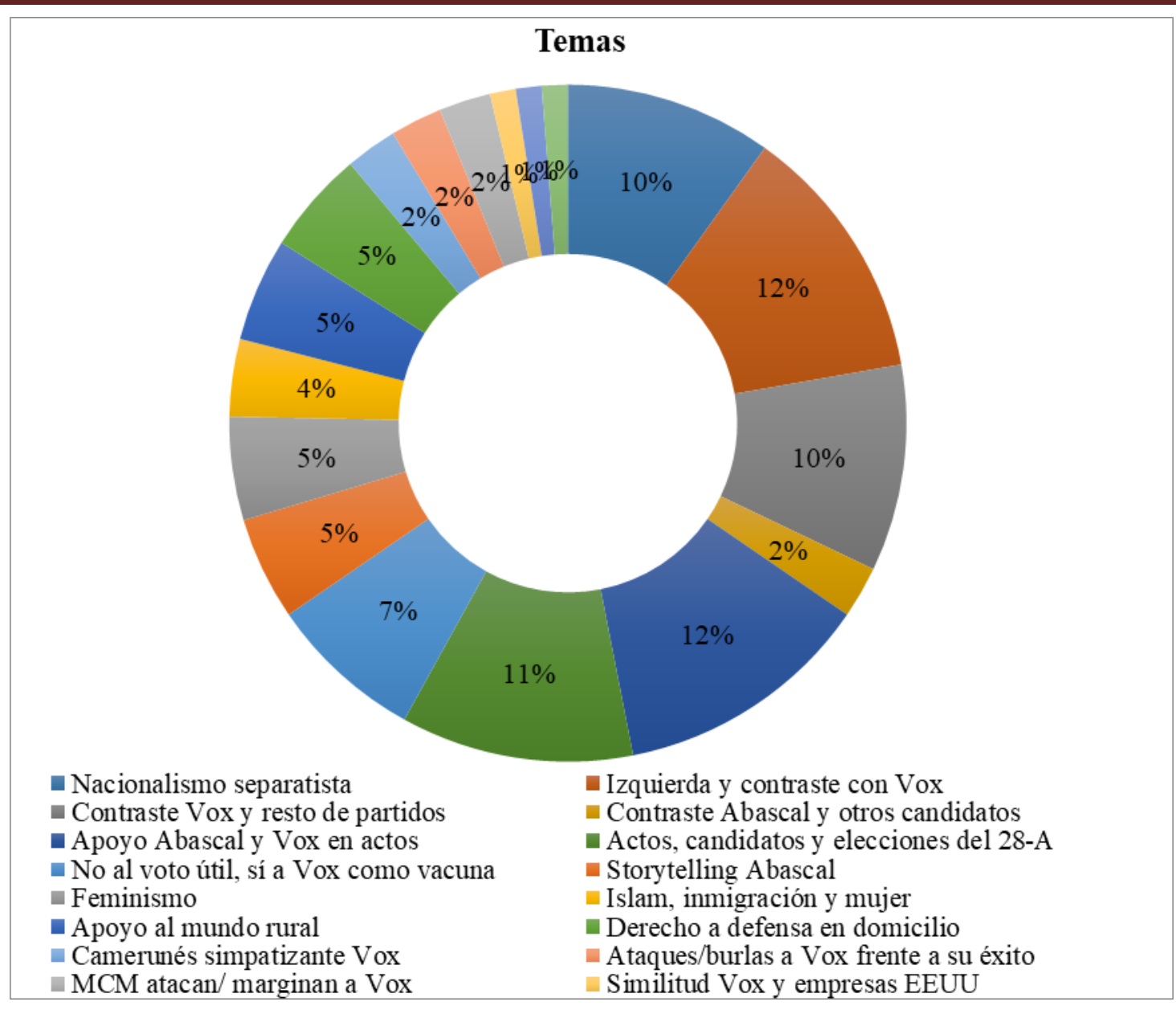

Gráfico 1: temas del total de las publicaciones que componen la muestra.

Fuente: elaboración propia.

Los ejes peligro-enemigo protagonizan más de la mitad de las publicaciones (56\%). Por un lado están la izquierda y su contraste con Vox (12\%), el nacionalismo separatista (10\%), el feminismo $(5 \%)$ y el islam, la inmigración y la mujer (4\%). Frente a ellos encontramos a Vox que funciona como un antídoto o vacuna $(7 \%)$. Se subraya la diferencia de la formación respecto al resto de partidos en general (10\%) y de su líder frente a otros dirigentes $(2 \%)$. Se detallan las características especiales y determinantes de la historia personal de Abascal por medio de la narrativa o storytelling $(5 \%)$.

A la hora de construir la identidad de grupo, como veremos en detalle, se apuesta, además de por la presencia continua de la bandera como símbolo de la unidad y tradición de España, por el apoyo al mundo rural (5\%). El autoritarismo se materializa en el derecho a la defensa en el propio domicilio (5\%). Los otros dos temas que centran casi una cuarta parte del discurso son el apoyo de simpatizantes al líder y al partido (12\%) y la presentación de actos y candidatos de cara al 28-A $(11 \%)$.

\subsection{Enunciadores en el texto}

Una vez obtenido el espectro temático, abordamos quién es el enunciador o enunciadores principales del mismo. Hemos tomado las categorías secundarias que aglutinan algunas enunciaciones del análisis narratológico, con personajes y objetos. El principal enunciador en el texto es el líder de la formación, Santiago Abascal, en un $42 \%$ de las publicaciones. Le sigue muy de lejos el secretario 
general, Ortega Smith (9\%). En otras publicaciones (9\%) el protagonismo se comparte entre varios líderes de la cúpula de Vox. También son importantes los manifestantes (6\%), simpatizantes (5\%), ciudadanos de a pie en el rol de padres o militares (4\%), personajes de la historia o de la cultura popular (4\%) y objetos que funcionan como sinécdoques $(4 \%)$.

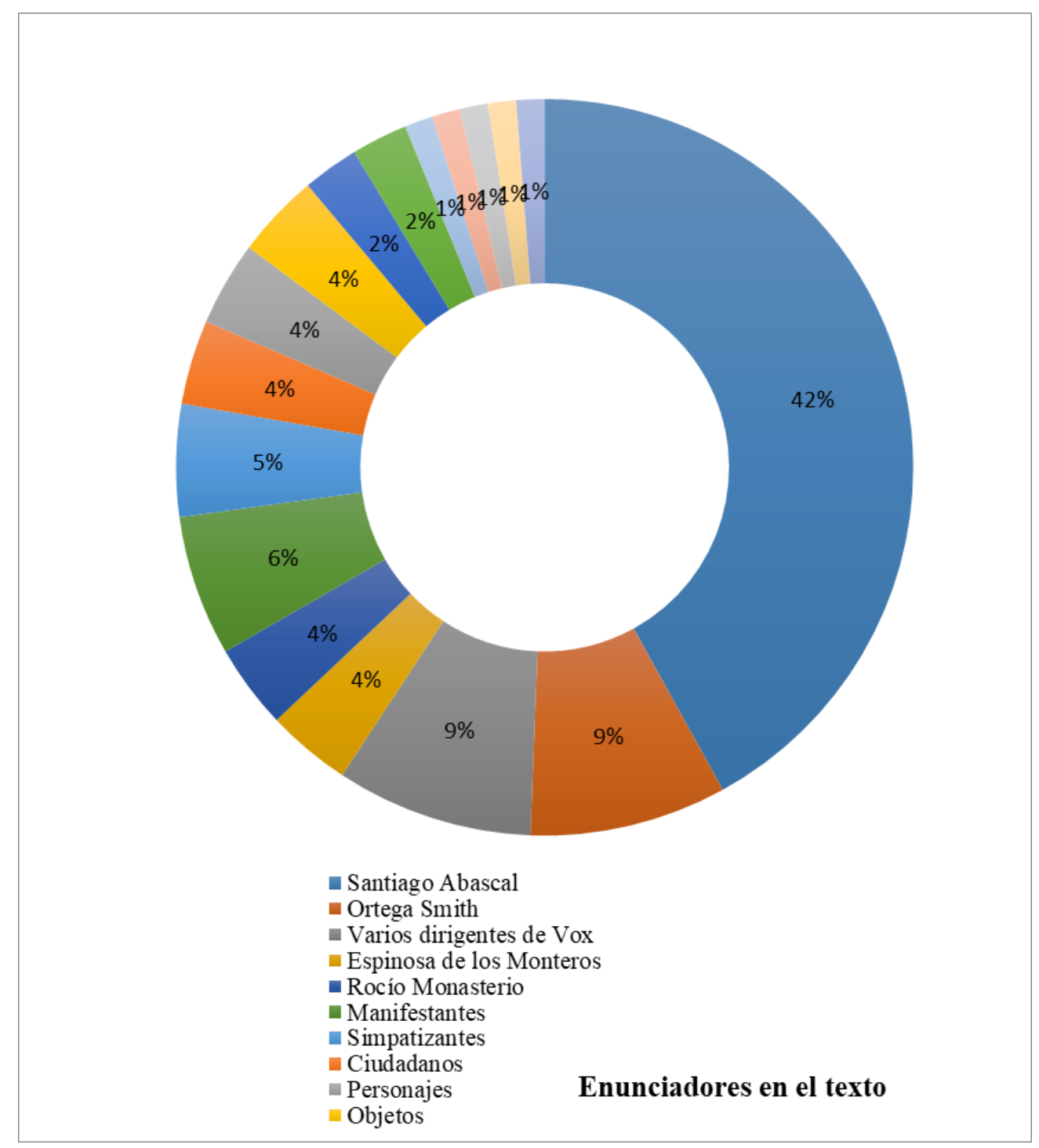

Gráfico 2: enunciadores del texto en los mensajes de Vox en Instagram.

Fuente: elaboración propia.

El hecho de que Abascal sea el enunciador en el texto de casi la mitad de las publicaciones coincide con el fenómeno de personalización e hiperliderazgo (Gil-Ramírez, Gómez de Travesedo-Rojas y Almansa-Martínez, 2019) en el actual panorama político español e internacional. Este hecho encaja con la mal llamada americanización o globalización de la política, que da al líder más peso que al propio partido.

\subsection{Publicaciones con mayor nivel de interacción}

Hemos evaluado el nivel de interacción de cada tipo publicación de Vox en Instagram procesando el número de me gusta y comentarios en el caso de que se tratara de carruseles (vídeos o combinados) o 
de imágenes (fotografía, meme, cartel o portada de medio) y el número de reproducciones y comentarios en el caso de que fueran vídeos.

Las veinte publicaciones que presentan un mayor nivel de interacción superan los 35.000 me gusta y comentarios (carruseles e imágenes) y las 145.000 reproducciones (vídeos).

La mayoría de las publicaciones (75\%) que más interacción logran en el período de estudio (28 de febrero - 28 de abril) se publican durante la campaña electoral (11-26 de abril), la jornada de reflexión o el mismo día de las elecciones. Esto demuestra que no sólo la actividad de los partidos es más intensa durante estas dos semanas (sino también la de los ciudadanos en relación a estos.

Es importante señalar que pese a que los memes representan únicamente el 5\% del total de la muestra (cuatro de las 81 publicaciones) tres de ellos están entre las veinte publicaciones con más interacción del período de estudio. Además, uno de los vídeos que logra el cuarto puesto en nivel de interacción, protagonizado por Espinosa de los Monteros, incluye al final del mismo un meme del dirigente bajo la expresión "thug life".

Este significante, muy popular en los vídeos de YouTube y en los propios memes, combina las palabras "thug life", la imagen de unas gafas de sol, un porro y la canción "The Next Episode" que el rapero Dr. Dre grabó junto a Snoop Dog, Kurupt y Nate Dogg. El objetivo es significar, a través de la ironía, que alguien se ha comportado, coloquialmente hablando, como "el amo" o "jefe" al dominar por completo una situación. En este caso, Espinosa de los Monteros se dirige con un megáfono a una periodista de Cuatro que le hace una pregunta diciéndole: "Cuatro, no moleste". Este caso muestra el éxito del meme como tipo de discurso en la interacción entre Vox y sus seguidores en Instagram, y merecería un estudio completo a parte.

Los cuatro grandes enemigos a los que ya hemos hecho referencia como ejes del discurso acaparan más de un tercio (35\%) de las 20 publicaciones que más interacción logran. Dentro de éstas, el enemigo izquierda y su contraste con Vox es el tema que más se repite. Destacan también las publicaciones que muestran el apoyo al líder y al partido o bien el contraste entre el líder y los demás candidatos $(15 \%)$.

El enunciador en el texto en la mayoría de estas publicaciones (45\%) es Santiago Abascal o éste en contraste con sus oponentes. También juegan un papel importante los simpatizantes y ciudadanos ( $25 \%$ de las publicaciones).

\subsection{Funciones del lenguaje, significantes clave y significados}

Hemos procedido a abordar las funciones, significados y significantes de los discursos de Vox en Instagram, porque nos proporcionan una buena base de observación de los discursos recurriendo parcialmente a esta metodología discursiva (Van Dijk, 2001; y 2005). Como sabemos, el análisis en detalle de esta metodología es especialmente útil para describir la conexión entre lenguaje, ideología y estrategias de persuasión.

Si atendemos a la función del lenguaje que predomina en las veinte publicaciones con mayores niveles de interacción observamos que se trata claramente de la conativo-apelativa. El objetivo es influir en el comportamiento del receptor. También son importantes las funciones poético-estética y expresivo-emotiva. El 30\% de las publicaciones se enmarcan en la función conativo-apelativa pero otro $35 \%$ la combinan con la poético-estética y un 30\% con la expresivo-emotiva. Se trata de casos en los que, además de movilizar el apoyo y el voto, se busca captar la atención de los usuarios por el 
uso que se hace de las imágenes y la música o los enunciadores en el texto expresan abierta y marcadamente sus emociones y sentimientos. Como veremos, la emocionalización es clave como estrategia de Vox.

Los significantes clave de las veinte publicaciones con más interacción tienen relación directa con el campo semántico de la batalla: patria, traición, lucha, resistencia, libertad, perseguir, inmovilizar, agonizar, perder, fuego, quemar, miedo, esperanza y valentía. En este lenguaje oposicional claro, Vox, de forma sinecdóquica, representa a España y al pueblo español que es patriota, bueno, decente, firme y valiente. El otro bando, que capitanea la izquierda, representa todos los peligros y amenazas. En línea con lo anterior, se construyen metáforas muy claras: España-Vox es nación, patria, gente, casa, familia, abuelos, padres e hijos. Las dos proyecciones semánticas fundamentales presentan a Vox como castigo o correctivo, (a modo de policía o ejército imponiendo la ley y el orden y disciplinando a la izquierda) o como auxilio y ayuda, (guardias o bomberos que prestan ayuda y sofocan el incendio).

En las fusiones conceptuales localizadas (Fauconnier, 2005), para ser España-patria-gente-casa, Vox se construye no como un partido político sino como un movimiento patriótico o espontáneo de base, formado por ciudadanos que necesitaban defenderse, frente a una agresión sufrida sin motivo. De ahí la importancia de subrayar que Vox lo integran personas con sentido común, humildes, trabajadores, obreros, currantes, agricultores y hombres de campo. Para ello, se emplean las fusiones y proyecciones metafóricas del estilo de "currantes del pladur", "España del pladur", "España que madruga" o la "realidad del pladur".

\section{Discusión y comentario de los ejemplos más relevantes}

\subsection{Ejes del discurso}

Los ejes vertebradores del discurso de Vox en Instagram son los mismos (separatismo, inmigración musulmana, feminismo e izquierda) que apuntamos en la aproximación inicial del marco teórico.

\subsection{Estrategias de comunicación}

Las principales estrategias comunicativas en esta red social coinciden con las del nativismo, el culto a las normas y convenciones, y la mente cerrada que describimos en el marco teórico. Se trata de:

- Crear un enemigo interno y externo.

- Construir la identidad del grupo-comunidad por medio de narrativas de pertenencia que se contraponen a esos enemigos.

- Eliminar las diferencias dentro del grupo.

- Denunciar el quebrantamiento de la ley y demandar el mantenimiento y fortalecimiento de la ley y el orden.

- Emocionalidad, agresividad y explotación del miedo (hay una especie de estado de sitio que requiere protección para el grupo-España).

- Rechazar la complejidad y simplificar el lenguaje.

A continuación presentamos ejemplos concretos que detallan el uso de estas estrategias.

\subsubsection{Creación de un enemigo interno y externo}

La agrupación de un enemigo común, de grandes dimensiones, en forma de partidos oponentes, invasiones extranjeras o terroristas y golpistas separatistas o feministas, es una estrategia clara. Por 
ejemplo, el uso del lenguaje que vincula significantes asociados a la Guerra Civil y a tiempos pasados (comunistas, Frente Popular) con significantes asociados al más reciente terrorismo y separatismo.

En la publicación 35 de la muestra, un vídeo de un fragmento de un discurso improvisado de Abascal en Tarancón (Cuenca), lo refleja claramente:

"No os dejéis asustar, que ya sé que no, pero no os dejéis asustar con el falso discurso del voto útil (...) Vox es el único partido que va a demostrar que es capaz de detener el avance del Frente Popular de socialistas que han pactado con los comunistas, que han pactado con los separatistas y han pactado con los amigos de los terroristas (...) ¡Viva España!” (Abascal, Discurso en Tarancón, 5 de abril de 2019).

Otro vídeo de Instagram (P. 38) muestra cómo la agrupación de significantes de varios colectivos demonizados organiza un enemigo de mil cabezas frente al que se opone el partido:

"Estamos hartos de ver, que nuestros políticos al que protegen es al desleal, es al enemigo de España, es al okupa, es al mantero, es a las feministas radicales. Son aquellos que representan lo que no somos la mayoría de los españoles, que somos leales a España y cumplidores" (Monasterio, Discurso en Leganés, 7 de abril de 2019).

La redundancia e insistencia en las identificaciones entre grupos opositores formando un enemigo ensamblado de enormes dimensiones permite al partido aumentar su propia importancia y presentarse como única alternativa (P. 53):

"Separatistas, separatistas golpistas, comunistas y los amigos de los terroristas nos reciben por toda España en nuestros actos públicos. Tratan de amedrentarnos. Decretan los socios de Pedro Sánchez la alerta antifascista al día siguiente de las elecciones andaluzas para dejar bien claro que no creen en la democracia ni en la voluntad del pueblo español. Lo hemos visto este fin de semana, con contenedores ardiendo, con adoquines lanzados, con agresiones. Con gentes de Vox que han visto su bandera de España arrancada de las manos y arrojada al Urumea (...). Encapuchados, embozados, amenazando, insultando a la gente que vamos a cara descubierta" (Abascal, Discurso en Valladolid, 16 abril de 2019).

La izquierda es uno de los enemigos obsesivos de Vox. Ésta, al igual que los separatistas, es además violenta (P. 53):

"Permitidme que empiece solemnemente responsabilizando a Pedro Sánchez y al Partido Socialista del clima de violencia de estos meses y de esta campaña (...) Pero no nos equivoquemos todos esos que vienen a recibirnos a los mítines no son más que la vanguardia, la partida de la capucha y de la porra de la dictadura progre que representa Pedro Sánchez (...) Aquí la violencia siempre la practican los mismos" (Abascal, Discurso en Valladolid, 16 de abril de 2019).

Se lanzan, además, invectivas deslegitimadoras contra ella como se observa en P. 58. La izquierda, pese a haber conformado partidos políticos y gobernar más de la mitad del período democrático (PSOE) "nunca ha aceptado la democracia” (Abascal, Libertad Digital, 19 de abril de 2019). 
RLCS, Revista Latina de Comunicación Social, 77, 203-229

[Investigación] DOI: 10.4185/RLCS-2020-1455 | ISSN 1138-5820 | Año 2020

\subsubsection{Construcción de la identidad del grupo-comunidad por medio de narrativas de pertenencia que se contraponen a los enemigos}

El cierre en torno a una comunidad, con el nativismo y la creación de un enemigo imaginario, son rasgos que emergen con fuerza en la frecuencia de los ítems. Está presente la simplificación en torno a los valores centrales que hemos señalado tanto para el partido como para la mentalidad autoritaria y cerrada citada previamente.

Para el desarrollo de su identidad grupal, Vox recurre a las simbologías patrióticas que identifica con su propio grupo, apropiándose de ellas. La " $\mathrm{X}$ " del nombre del partido es una cruz simbólica que enlaza directamente, también, con las cruces de Cruzados.

La bandera de la nación que representa la unidad y la libertad que quieren romper los separatistas y la izquierda, se convierte en el símbolo del partido. Los mítines rebosan de banderas de Vox entremezcladas con banderas de España en un intento por significar que son lo mismo. La parte por el todo, la sinédoque, de nuevo emerge como estrategia central. El lugar en el que se celebran los actos del partido habitualmente, además de las plazas de toros, es la Plaza de Colón en Madrid que es el espacio con la bandera oficial de mayores dimensiones del país. La bandera de España es, además, uno de los emojis que más aparecen en las publicaciones. Por estas asociaciones simbólicas, el partido se asemeja a la nación y se tiñe de grandes dimensiones, nutriéndose de las asociaciones semánticas de la misma.

El lenguaje del simbolismo mítico y religioso ancla al partido también en una identidad en oposición al laicismo. Un ejemplo que lo muestra con claridad es la publicación 60 (P. 60) que, en forma de vídeo, recoge un fragmento de un discurso de Abascal en Murcia que responde a estos valores:

"En mi pecho, hasta esta campaña, sólo llevaba el escapulario con el sagrado corazón de mi abuelo y que luego era de mi padre. Ahora, después de estos días intensos y de tantas esperanzas, os tengo que decir que llevo el Cristo de la buena muerte que un legionario me ha prestado hasta el día 28. La Virgen de Covadonga bendecida que una mujer llena de emoción me entregó, precisamente, a los pies de la santina. La Cruz de San Benito. ¡Y no sé con qué más llegaré al final de campaña! (Abascal, Discurso en Murcia, 21 de abril de 2019).

\subsubsection{Eliminación de las diferencias dentro del grupo}

Para generar un lenguaje oposicional sencillo, Vox crea un conjunto de valores simples. Las publicaciones en las que aparecen los candidatos pero no ponen en escena discursos, que muestran el ambiente en los mítines y el apoyo a Vox y a sus líderes, buscan proyectar el concepto de que Vox es un movimiento popular, sin diferencias internas. Este recurso a la base popular se combina con un lenguaje simple (P. 73):

"Vox es mucho más que eso. Es un movimiento patriótico en defensa de las cosas más importantes (...) Pero, ¿habéis visto el vídeo del currante del pladur? Lo ha visto toda España e, Ismael, que así se llama, ese currante, ese español honrado, que representa a la España que madruga, ha prestado un servicio excelente frente a un progre que le quería buscar las cosquillas. Y que le ha dado no una lección, le ha dado 18. Una detrás de otra en solo 3 minutos. Porque nosotros reivindicamos la España del pladur frente a la locura de los progres que se piensan que el obrero está preocupado con el heteropatriarcado. ¿Qué se piensan? ¿Que el agricultor, que el hombre del campo, está preocupado por el lenguaje inclusivo (...)? La gran ventaja que tenemos para derrotar a la dictadura progre, es que han perdido la cabeza definitivamente. Que se enfrentan al sentido común, a la realidad, a las 
cosas normales y a lo que a toda la gente normal nos enseñan en nuestra casa. ¿Sabéis por qué vamos a ganar? Porque la puñetera realidad del pladur se enfrenta a sus neuras, a sus tonterías, a sus fanatismos y no tienen ninguna posibilidad de victoria" (Abascal, Discurso en la Plaza de Colón, 26 abril de 2019).

El lenguaje oposicional permite crear un sistema cerrado de creencias que se resume finalmente en la opción de Vox como única posible. En la publicación 74 (P. 74) encontramos un carrusel de fotografías del acto de cierre de campaña en la Plaza de Colón que se acompañan de este fragmento del discurso de Abascal: "O la desaparición o la continuidad histórica de nuestra Patria; o miseria socialista o prosperidad de nuestros hijos y nietos; o la dictadura progre o la libertad de los españoles, entre la antiespaña o la España Viva" (Abascal, Discurso en la Plaza de Colón, 26 abril de 2019).

El mundo rural tiene una presencia clara en este retorno a valores primarios. Está representado, sirviéndose de nuevo de cadenas de conexiones en sinécdoque y simbolismo, por los toros, la caza, la pesca, los camioneros, e incluso el control de la inmigración ilegal y la defensa de los productos nacionales. En relación con estos dos últimos, se establece un paralelismo entre la inmigración ilegal y lo que califican como "la invasión de productos marroquíes de baja calidad", que es también una defensa de la tierra, del campo español. En la publicación 52 (P. 52) Ortega Smith explica durante una visita a El Ejido (Almería) que apoyarán a la agricultura "terminando de una vez por todas con la inmigración ilegal". También llama a poner fin a "la invasión de productos marroquíes de baja calidad" (Ortega Smith, Discurso en El Ejido, 15 de abril de 2019).

Por último en la publicación 20 (P. 20) encontramos una fotografía de Santiago Abascal sosteniendo un águila y sonriendo. Se acompaña de los hashtags o etiquetas: \#Naturaleza \#Caza \#Pesca \#Agricultura \#Ganaderia \#Tauromaquia \#MundoRural \#Fotografía. Puede apreciarse la cadena de conexiones hacia un simbolismo de amplísima extensión.

\subsubsection{Normativismo: la ley y el orden como discursos dominantes}

El normativismo, la obediencia a la ley y el acento en la rigurosidad penal son aspectos que conectan con la personalidad autoritaria que rige en la dinámica de los grupos conservadores como Vox. El partido incide en contenidos que acentúan los castigos y dureza penal ante delitos:

P. 55: "Vamos a poner encima de la mesa la ilegalización de los partidos separatistas de una vez por todas" (Abascal, Discurso en Granada, 17 de abril de 2019).

P. 9: "Somos el único partido que defiende mucha más severidad en las penas, es más, que se queden en la cárcel de por vida los violadores reincidentes" (Monasterio, Entrevista en El programa de Ana Rosa, 12 de marzo de 2019).

En esta pieza, se relata en tonos dramáticos y apocalípticos la relajación penal que ha traído el gobierno en los últimos tiempos (P. 18): "Una mujer maltratada, que está en su domicilio, a la que viene su maltratador y entra en su domicilio y quiere acabar con ella, esa mujer, si coge un cuchillo o acaba con el maltratador, o lo hiere, tiene todo el derecho del mundo. Está defendiéndose (...) Esa niña que fue violada en Azuqueca por cuatro menores que ahora están en la calle. De esa seguridad sí que queremos hablar en Vox y de penas mucho más severas para todos estos violadores reincidentes" (Monasterio, Entrevista en Los desayunos de TVE, 22 de marzo de 2019). 
Mención aparte merece el uso del lenguaje militar. Simboliza la obediencia a la norma y es un código poderoso de simplificación informativa. Las órdenes y mandatos militares ("¡Vamos al ataque y vamos a por ellos!”, “¡Por España!”, “¡Viva España!”) cumplen la doble función de reducir carga semántica y llamar al recuerdo nostálgico. Dentro de este lenguaje bélico-militar, la metáfora de la batalla por la continuidad de España en un momento decisivo, en un tiempo que es kairós, es clave en el discurso del partido. En esta batalla, Vox es el único "luchador" que puede derrotar a los enemigos clave de España porque la propia formación es en sí misma España. Se aprecia claramente en las imágenes, las palabras e, incluso, la música que acompaña las publicaciones de Instagram. Ante estos enemigos, el partido se alza como un muro, ejército o guardián protector capaz de sentar el orden y la justicia de nuevo en el país:

P. 33: “¡Vox somos ahora la resistencia! (...) Hemos venido aquí para decir que la España viva tiene mucha más fuerza que aquellos que quieren ver a España muerta. Y el día 28 de abril vamos a derrotarlos. Vamos a demostrar que lo verdaderamente útil es ponerse en pie (...) ¡Viva España!" (Abascal, Discurso, 3 de abril de 2019).

P. 5: "Bienvenidos a la resistencia desde Europa (...) Gracias a todos aquellos que creen que salvar a Europa todavía es posible" (Ortega Smith, Discurso en el Parlamento Europeo, 6 de marzo de 2019).

En la lista de candidatos al 28-A (P. 15) se subraya la presencia de tres generales "que han dedicado su vida en el Ejército al servicio de España". El centro de la publicación es una fotografía del General Alberto Asarta que interpela directamente al usuario-espectador con mirada desafiante y brazos cruzados. Se emplean los hashtags o etiquetas \#ejército y \#Voxavanza. El color verde de Vox es también el del Ejército de Tierra y el de la ropa y equipamiento de los cazadores.

\subsubsection{Emocionalidad, agresividad y explotación del miedo}

La promoción de la severidad penal y la denuncia de la laxitud de las autoridades actuales persigue además otro fin, que es el de exhortar al miedo y el consecuente odio hacia el agresor.

P. 34: "El enemigo de la libertad, el enemigo del progreso, el enemigo de la democracia, el enemigo de la familia, el enemigo de la vida, el enemigo del futuro se llama invasión islamista (...) Que a nadie le quepa duda: VOX va a seguir denunciando y combatiendo la invasión islamista. Tenemos que estar vigilantes y tenemos que expulsar a cualquiera que suponga una amenaza para la seguridad de los españoles" (Ortega Smith, Declaraciones en los Informativos de Antena 3, 4 de abril de 2019).

Abundan en el discurso de Vox descripciones catastrofistas de situaciones imaginarias de ataque a personas particulares, para situar a los individuos en entornos amenazantes que puedan desencadenar odio y miedo:

P. 21: "Hemos dicho que en su casa, si son asaltados, tienen derecho a defenderse: con un palo, con el cenicero, con el cuchillo de cocina, con la licencia que les haya dado el Estado. Si un español es asaltado en su casa y ve cómo amordazan a su familia, cómo intentan violar a sus hijas, tiene el derecho y tiene el deber de defenderlas y no de esperar a que llegue la policía" (Abascal, Discurso en Ciudad Real, 24 de marzo de 2019).

P. 22: "Ahora os pido que, por un momento, imaginéis que cualquiera de vosotros, vuestros padres, o si queréis pensad por un momento en vuestros abuelos, que están tranquilamente en casa un domingo $\mathrm{y}$, de repente, dos criminales con pasamontañas entran en el jardín de vuestra casa. Le pegan dos tiros con silenciador a vuestros perros y entran a la casa. Le pegan una paliza a vuestro abuelo y a 
vuestra abuela, de 78 y de 72 años. Una paliza que podía haber sido mortal... (...) Esa organización criminal estuvo al límite de haber dejado a estas dos personas muertas" (Ortega Smith, Discurso en Martos -Jaén-, 25 de marzo de 2019).

La expresión de las emociones primarias del miedo, la ira, el valor o arrojo inunda las publicaciones encajando bien con la necesidad de calor emocional en el mundo desagregado y relativista del siglo XXI:

P. 30: "Los españoles que hemos sobrevivido a los tiros en la nuca y a las bombas lapa, no nos íbamos a amedrentar con cuatro cursis cantando a Lluis Llach" (Abascal, Discurso en la manifestación de Barcelona, 31 marzo de 2019).

El discurso fuertemente emocional coloca a los electores en posiciones de inseguridad e incertidumbre. El partido dice defender a los votantes contra el miedo pero es el primer exhortador del mismo en sus discursos y denuncias. Esta estrategia de aludir constantemente a dicho sentimiento lo introduce y lo trae constantemente a primera línea, como se aprecia en el lema: “ ¡Sin miedo a nada ni nadie! ¡Por España! ¡Viva España!”.

\subsubsection{Rechazo de la complejidad y el lenguaje simplificador de carga}

Si analizamos el discurso de Vox notaremos que dominan expresiones relacionadas con un lenguaje simple y natural: familia, abuelos, mujer, hijos, tradición, campo, España, vida, patria, espíritu progre, dictadura.

Vox tiene una tendencia muy clara a la agrupación de conglomerados semánticos amplios en oposiciones simples (enemigos/amigos, defensores/agresores, víctimas/verdugos, leales/traidores, cobardes/valientes, falsos/sinceros) que ordenan la realidad en un maniqueísmo básico. Se presenta, incluso, como alternativa al discurso democrático, basado en ejes racionales, de consenso y de progresismo político.

Existe una clara distancia entre el conjunto de isotopías semánticas asociadas al discurso político democrático convencional y el conjunto de isotopías semánticas del discurso extremista de Vox. Esta diferencia se manifiesta en constantes frases que disponen estos dos estilos como si fueran dos bandos de una contienda. Abascal afirma en la publicación del 3 de abril (P. 33): "Y decirles a los valientes que tienen un partido para valientes que va a dar la batalla contra todas las imposiciones de lo políticamente correcto".

La patria se asocia también a la paternidad y a la familia, para favorecer la cadena de identificaciones que termina en el propio líder que exhibe a menudo su condición de padre. Las imágenes de padres de familia que aparecen en el vídeo del Día de Padre del 19 de marzo (P. 16) incluyen explícitamente a militares. De esta manera se unen ambos valores y se simplifica el discurso.

La simplificación de la figura del líder, Abascal, con rasgos personales sencillos y heroicos es clara en sus construcciones de storytelling político. En la publicación del 14 de abril (P. 51) tienen un gran protagonismo las voces e imágenes de mujeres, especialmente, las de la familia de Abascal: su abuela, su madre y su hermana exponen cuál es el rasgo que lo identifica: la fortaleza.

Como un rasgo peculiar dentro del lenguaje simplificador aparece el ataque a los medios de comunicación y sus discursos. El ataque a los medios de masas es también un rasgo de claro rechazo 
a la sociedad de la información y puede servir de defensa a votantes que también rechacen esa sociedad por su complejidad y sobrecarga, en un claro rasgo de mentalidad cerrada.

Vox comparte con los partidos populistas el ataque a los medios y una clara criminalización de todos los informadores que son contrarios a sus ideas o críticos con ellas. Así, es frecuente que sus portavoces hablen de noticias falsas, de medios de la mafia de izquierdas o de campañas orquestadas contra el partido. En la publicación del 28 de marzo (P. 26), Abascal explica cómo se orquestan las noticias falsas contra Vox. Los medios, especialmente los de izquierdas, y las cloacas de los partidos trabajan para difundir mentiras y bulos y, así, propagar el miedo a Vox.

\section{Discusión}

Las veinte publicaciones con un mayor nivel de interacción nos han servido para confirmar las principales aristas del discurso específico de Vox, en el mundo de la red social Instagram. Existe una clara coherencia y unidad en el uso de imágenes, textos, alusiones culturales, simbolismos, que giran de manera insistente en torno a los ejes temáticos que hemos destacado de modo general. El refuerzo del grupo mediante la creación de enemigos, el normativismo, el nativismo, la simplificación y la exaltación emocional de un lenguaje belicista y mitológico a la vez es de nuevo evidente, si bien adaptada al código del usuario, mediante los memes, los juegos de palabras o la apelación imaginaria al combate, al miedo o al activismo.

Estos resultados coinciden con la investigación previa existente en torno a la derecha radical, así como con las aportaciones sobre la influencia política de movimientos radicales mediante el uso de las redes sociales. Éstas se presentan como una nueva esfera donde el hiperliderazgo narcisista, la homofilia y mentalidad de grupo, el refuerzo identitatio y la apelación conativa a la pertenencia encuentran un terreno idóneo.

La muestra analizada encaja también con la aproximación temática inicial, y nos señala el tipo de mensajes y lenguajes de Vox en Instagram. Destacan de nuevo los memes, que suscitan más respuestas. Se confirma el tono apelativo y conativo, los campos semánticos son los mismos que en el conjunto de comunicaciones de esta formación, que tiene como estrategia efectiva la eliminación de la complejidad y un lenguaje oposicional simple. Las operaciones discursivas siguen centradas en la metaforización, las fusiones conceptuales, sinécdoques, y extensiones simbólicas.

Es importante señalar que Vox ha encontrado en su estrategia comunicativa básica un filón para acercarse al lenguaje icónico, simple y de grupo cerrado que se da en las redes de uso mayoritariamente juvenil. La misma estrategia que le sirve para dirigirse a todas las capas sociales, ampliando las asociaciones semánticas de sus metáforas, le permite acceder, con las adaptaciones adecuadas, al mundo de las redes sociales como Instagram.

\section{Conclusiones}

En las publicaciones de Instagram que hemos estudiado, Vox conserva los cuatro ejes de discurso oposicional que nos lo muestran, tal y como hemos definido, como un partido de derecha radical tendente a la mentalidad cerrada y al dogmatismo: los nacionalismos periféricos, la inmigración musulmana, el feminismo y la izquierda son los temas clave. Frente a ellos el partido se sitúa como único antídoto posible.

En el análisis multi-metodológico que hemos seguido, Vox se confirma como un partido que usa como estrategia clave la selección temática, y un lenguaje propio. Esta estrategia tiene múltiples 
ventajas. Simplifica el discurso a muy pocos elementos -con un programa político breve-, lo que favorece la comprensión de los electores sobrecargados de redundancia informativa en ciertos temas.

Los símbolos, el lenguaje y los contenidos en Instagram de Vox, muestran con claridad absoluta la adaptación total a la estrategia y dinámica propias del nativismo, el culto a la nostalgia, el tradicionalismo y la sumisión a las normas y leyes como elementos constitutivos de su discurso. El autoritarismo y la hiperpresencia del líder, el cierre en torno a una comunidad sin diferencias económicas o de clase, el recurso a los valores militares o el uso de las emociones y el miedo a enemigos imaginarios, son algunos de los rasgos concretos que de nuevo encajan absolutamente con las estrategias de la mentalidad autoritaria descrita hace ya casi un siglo para formaciones de la derecha radical.

El uso de la metáfora combinada con la sinécdoque es fundamental en la construcción de las narrativas identitarias nucleares de su discurso. Vox es un partido que se nos aparece marcado por asociaciones simbólicas, con cadenas de relaciones semánticas que lo vinculan con un todo, y lo hacen susceptible de una identificación absoluta con el país. Vox es España, la bandera, la nación, la patria, que a su vez nos remite al concepto de casa, hogar, familia y padre.

La estrategia de asociaciones mediante sinécdoques y fusiones de significados ha cuidado especialmente la vinculación de todos los discursos con la figura de un líder único, hipostasiado en las redes como Instagram. Esta última figura la encarna claramente Santiago Abascal, del que en las redes sociales, por su especial capacidad para la presentación narcisista o hiperpersonal, se refuerza su importancia. En las imágenes y vídeos de Instagram, se destaca su especial destino e historia personal. Acostumbrado a servir a otros desde muy joven, el líder encarna las virtudes propias del héroe clásico entre las que destaca la fortaleza. Constituye la propia esencia de la formación, encarna al ideal, y al mismo tiempo, al hombre común. La capacidad del partido para personalizar en esta figura todos los valores que moviliza, ha encontrado en las redes como Instagram un vehículo idóneo.

Es importante señalar que las publicaciones de Instagram, tanto a nivel de contenido como de forma, no se dirigen a un simple usuario de una red social, sino que construyen a un activista. El discurso es el propio de un movimiento de resistencia civil, que interpela al ciudadano para que sea valiente y se comprometa, junto a sus iguales, a hacer frente a poderes abusivos e injustos. Nos encontramos así con el cierre del grupo reforzado, con la búsqueda de la mentalidad grupal que encaja bien con el activismo combativo.

Los usuarios seguidores de Vox en Instagram son, en la estrategia diseñada del partido, los integrantes de una protesta espontánea nacida del hartazgo y el cansancio ciudadano. En este sentido, el apoyo de los simpatizantes al partido se representa visualmente a través de numerosas personas que sostienen banderas de España, como si se tratara de manifestantes, más que de asistentes a un mitin. El marco de referencia es claramente el de la política no convencional. Y las asociaciones semánticas con la guerra, la lucha, y las batallas históricas, no hacen sino reforzar este aspecto.

Vox es, por tanto, no un partido de derecha radical únicamente, sino un movimiento social de base o plataforma ciudadana, donde los jóvenes constituyen el núcleo. En este sentido, el discurso en Instagram emplea el código propio de este segmento. En la muestra analizada, hemos hallado vídeos breves, de 40 o 50 segundos, o carruseles que combinan varios vídeos cortos, el formato más usual para esta población. Entre las publicaciones con más interacción destacan los memes y, además de la función conativo-apelativa propia de la política, en los mensajes destacan la función expresiva y la poético-estética que ponen el acento en los estados de ánimo, pero también en un tipo de estética que puede atraer claramente a este grupo. 
El conjunto de las estrategias, lenguaje y discurso del partido Vox en la red social Instagram nos ofrece, por tanto, una importante muestra de un nuevo estilo comunicativo en la política actual española, que recurre a elementos y herramientas bien conocidas por los analistas de la mentalidad grupal cerrada. Es sin embargo novedosa la combinación de elementos que presenta este partido, que, siendo de raigambre democrática, se orienta contra los principales conceptos, estrategias y discursos de la política democrática en España. Ahí reside en gran medida su originalidad: en traer hasta las redes sociales del siglo XXI estrategias y lenguajes que provienen de tiempos lejanos.

\section{Referencias bibliográficas}

Abascal, S. (2013). Carta a Mariano Rajoy. https://www.santiagoabascal.es/

Abascal, S. (2019). Discurso en Santander el 28 de marzo de 2019. https://www.youtube.com/watch?v=1WY4HJlwukU

Abascal, S. (2019). Discurso en Covadonga el 12 de abril de 2019. https://www.youtube.com/watch?v=4mTFfdNRCtE

Abascal, S. (2019). Discurso en la Plaza de Colón el 26 de abril de 2019. https://www.youtube.com/watch?v=n Eh89UDng

Abascal, S. (6 de abril de 2019). Entrevista con Bertín Osborne en el programa Mi casa es la tuya. Telecinco.

https://www.telecinco.es/micasaeslatuya/programa-completo-integro-hd_2_2733705125.html

Alabao, N. (4 de diciembre de 2018). La guerra de Vox contra el feminismo. Ctxt. https:/ctxt.es/es/20181129/Firmas/23216/Nuria-Alabao-machismo-en-voxmasculinizacionneofascismo-Santiago-Abascal.htm

Adorno, T. W., Frenkel-Brunswik, E., Levinson, D. J., \& Sanford, N. R. (1950). The Authoritarian Personality. Norton.

Aladro, E., Valbuena, F. y Padilla, G. (2012). Redes sociales y jóvenes universitarios españoles: nuevos ejes de socialización. Austral Comunicación, (1), 27-40.

Aladro, E. y Villalba, S. (2013). Twitter como difusor de innovaciones. Interactividad y redes sociales. Visión Libros.

Altemeyer, B. (1981). Right-wing authoritarianism. University of Manitoba Press.

Aral, S., Muchnik, L., \& Sundararajan, A. (2009). Distinguishing influence-based contagion from homophily-driven diffusion in dynamic networks. PNAS, 106(51). https://doi.org/10.1073/pnas.0908800106

Aral, S. (2012). Social science: Poked to vote. Nature, (489), 212-214. http://doi.org/10.1038/489212a

Aral, S., \& Walker, J. (25 de enero de 2015). Tie Strength, Embeddedness \& Social Influence: Evidence from a large scale networked experiment. SSRN. http://dx.doi.org/10.2139/ssrn.2197972 
RLCS, Revista Latina de Comunicación Social, 77, 203-229

[Investigación] DOI: 10.4185/RLCS-2020-1455 | ISSN 1138-5820 | Año 2020

Araluce, G. (6 de enero de 2019). Un 62\% de los votantes de Vox atribuye su éxito en Andalucía a la política de Sánchez en Cataluña. El Español.

https://www.elespanol.com/espana/20190106/votantes-vox-atribuye-andalucia-politica-sanchezcataluna/366213821_0.html

Benedicto, J., Echaves, A., Jurado, T., Ramos, M. y Tejerina, B. (2017). Informe Juventud en España 2016. Madrid: Instituto de la Juventud (INJUVE).

http://www.injuve.es/sites/default/files/2017/24/publicaciones/informe-juventud-2016.pdf

Camacho, J. (25 de noviembre de 2018). Catalunya se cuela en el debate andaluz. El Periódico. https://www.elperiodico.com/es/politica/20181125/catalunya-irrumpe-elecciones-andaluzasciudadanos- pp-7166525

Camas, F. (28 de febrero de 2017). ¿Por qué votan menos los jóvenes en España? Metroscopia. http://metroscopia.org/por-que-vota-menos-la-gente-joven/

Campbell, J. (2015). El poder del mito. Capitán Swing.

Carpio, J. A. (30 de abril de 2019). Radiografía del voto: dime quién eres y te diré cómo votas. RTVE.es. $\quad$ http://www.rtve.es/noticias/20190430/datos-hablan-radiografia-del-voto-voto-grupos$\underline{\text { sociales/1930141.html }}$

Casaló, D., Flavián, C., e Ibáñez-Sánchez, S. (2018). Influencers on Instagram: Antecedents and Consequences of Opinion Leadership". Journal of Business Research, july 2018. https://doi.org/10.1016/j.jbusres.2018.07.005

Castro, C. (2 de diciembre 2018). ¿Quién cosecha los réditos del conflicto catalán en Andalucía? La vanguardia. $\quad$ https://www.lavanguardia.com/politica/20181202/453268445356/eleccionesandalucia-conflicto-catalan-estatut-impacto.html

Cea, N. (2019). Nivel de interacción de la comunicación de los partidos políticos españoles en Redes Sociales". MARCO (Marketing y Comunicación Política), (5), 41-56. http://www.usc.es/revistas/index.php/marco/article/view/6332

Cruz, M. (2019). Cataluña se dispara como preocupación y condicionó el voto del $44 \%$ de los electores". El Mundo.

https://www.elmundo.es/espana/eleccionesgenerales/2019/11/28/5ddfc28cfc6c835b058b4624.html

Del Teso, E. (30 de abril de 2020). Como tratar con la propaganda fascista sin futuro ni pasado. $L a U$. https://la-u.org/como-tratar-con-la-propaganda-fascista-sin-futuro-ni-pasado/

Del Teso, E. (2019). La izquierda, los discursos y los relatos. Trea.

Deusdad, B. (2013). El concepto de liderazgo político carismático: populismo e identidades. Opción, 19(41), 9-35. https://www.redalyc.org/pdf/310/31004101.pdf

El Confidencial Digital (19 de marzo de 2019). Vox se declara "liberal-conservador" en Francia. https://www.elconfidencialdigital.com/articulo/politica/vox-declara-liberal-conservadorfrancia/20190318170647123153.html 
Eldin, A. K. (2016). Instagram role in influencing youth opinion in 2015 election campaign in Bahrain. European scientific journal, 12(2), 245-257.

https://doi.org/10.19044/esj.2016.v12n2p245

Espartero, M. (16 de noviembre de 2019). Vox y Podemos fueron los partidos más votados por los varones menores de 30 años el 10-N. El Español.

https://www.elespanol.com/espana/politica/20191116/vox-podemos-partidos-votados-varones$\underline{\text { menores-anos/444955990 } 0 . \mathrm{html}}$

Evans, N. J., Phua, J., Lim, J., \& Jun, H. (2017). Disclosing Instagram influencer advertising: The effects of disclosure language on advertising recognition, attitudes, and Behavioral Intent. Journal of Interactive Advertising, 17(2), 1-12. https://doi.org/10.1080/15252019.2017.1366885

Fauconnier, G. (2005). Fusión conceptual y analogía. CIC. Cuadernos de Información y Comunicación, (10), 151-182.

https://revistas.ucm.es/index.php/CIYC/article/view/CIYC0505110151A

Fernández, G. (11 de diciembre de 2018). Las herramientas retóricas de la movilización de Vox. Eldiario.es $\quad$ https://www.eldiario.es/piedrasdepapel/herramientas-retoricas-movilizacionVOX 6 845225471.html

Fernández, R. (1 de abril de 2020). Número de usuarios activos mensuales de Instagram 2013-2018". Statista. https://es.statista.com/estadisticas/598856/numero-de-usuarios-activos-mensuales-deinstagram-en-septiembre-de/

Ferreira, C. (2019). Vox como representante de la derecha radical en España: un estudio sobre su ideología. Revista Española de Ciencia Política, (51), 73-98. https://doi.org/10.21308/recp.51.03

Filimonov, K., Russman, U., \& Svensson, J. (2016). Picturing the party: Instagram and party campaigning in the 2014 Swedish elections. Social media + society, julio septiembre, 1-11. https://doi.org/10.1177/2056305116662179

Francés, F. J. y Santacreu, O. A. (2014). Crisis política y juventud en España: el declive del bipartidismo electoral. Società, Mutamento, Política, 5(10), 107-128. https://core.ac.uk/download/pdf/32321975.pdf https://doi.org/10.13128/SMP-15408

Fromm, E. (1941). Escape from Freedom. Holt, Rinehart and Winston.

Galais, C. (2012). ¿Cada vez más apáticos? El desinterés político juvenil en España en perspectiva comparada. Revista Internacional de Sociología (RIS), 70(1), 107-127. http://revintsociologia.revistas.csic.es/index.php/revintsociologia/article/view/438 https://doi.org/10.3989/ris.2011.05.07

Galeano, S. (21 de febrero de 2019). El número de usuarios de Instagram en España crece hasta los 15 millones $(+15,3 \%)$ pero se estanca en las ciudades (2019). Marketing4ecommerce. https://marketing4ecommerce.net/numero-de-usuarios-de-instagram-en-espana-crece-hasta-los15-millones-pero-se-estanca-en-las-ciudades-2019/

Gallardo Paúls, B., y Enguix Oliver, S. (2016). Pseudopolítica. El discurso político en las redes sociales. Universidad de Valencia. 
RLCS, Revista Latina de Comunicación Social, 77, 203-229

[Investigación] DOI: 10.4185/RLCS-2020-1455 | ISSN 1138-5820 | Año 2020

Gil Grande, R. (2 de diciembre de 2018). Vox irrumpe con fuerza en Andalucía logrando 12 escaños y se pone de meta las generales. RTVE. http://www.rtve.es/noticias/20181202/extrema-derechairrumpe-parlamento-andaluz-12-escanos-obtenidos-vox/1847384.shtml

Gil Grande, R. (3 de diciembre de 2018). Claves del éxito de Vox: Cataluña, el descontento con la derecha española y los precedentes europeos. RTVE.

http://www.rtve.es/noticias/20181203/claves-del-exito-vox-andalucia-cataluna-descontentoderecha-espanola-precedentes-europeos/1847583.shtml

Gil Ramírez, M., Gómez de Travesedo Rojas, R. y Almansa Martínez, A. (2019). Politainment y personalización política. ¿De la televisión a YouTube? Revista Latina de Comunicación Social, (74), 1542-1564. http://www.revistalatinacs.org/074paper/1398/81es.html https://doi.org/10.4185/RLCS-2019-1398-81

Gould, R. (2019). Vox España and Alternative für Deutschland: Propagating the Crisis of National Identity. Genealogy, 3(64), 1-25. https://doi.org/10.3390/genealogy3040064

Guia, A. (2016). El reto del nativismo a la pluralidad e igualdad en las democracias liberales". Retos inaplazables en el sistema internacional, anuario 2015-2016, (8), 107-120. https://dialnet.unirioja.es/servlet/articulo? codigo $=5503288$

Janis, I. (1991). Victims of Group Thinking. Political Psychology, 12(2), 247-278. https://www.jstor.org/stable/3791464?seq=1 http://doi.org/10.2307/3791464

Jost, J. T., Glaser, J., Kruglanski, A. W., \& Sulloway, F.J. (2003). Political conservatism as motivated social cognition. Psychological Bulletin, (129), 339-375. https://psycnet.apa.org/record/2003-00782-003 http://doi.org/10.1037/0033-2909.129.3.339

Jung, Y.; Tay, Ashley; H., Terence; H., Judith; G., \& Yan H. (2017). Politician's strategic impression management on Instagram. Proceedings of the 50th Hawaii international conference on system sciences, 2195-2201. http://hdl.handle.net/10125/41420

Lovink, G., \& Rossiter, N. (2017). El supuesto digital: 10 Tesis. CIC Cuadernos de Información y Comunicación, (22), 13-18. https://doi.org/10.5209/CIYC.55953

Marina Braio, A. (16 de marzo de 2019). El auge de Vox en internet es mayor que el de Podemos en 2014, según un estudio. $A B C$. https://www.abc.es/espana/abci-auge-internet-mayor-podemos2014-segun-estudio-201903160208_noticia.html

Martín Plaza, A. (29 de abril de 2019). Vox irrumpe en el Congreso con 24 diputados y se sitúa como quinta fuerza con más de 2,6 millones de votos. RTVE.

http://www.rtve.es/noticias/20190429/elecciones-resultados-vox/1929067.shtml

Martín Plaza, A. (11 de noviembre de 2019). Vox se dispara hasta colocarse como tercera fuerza con 52 diputados, más del doble que en abril. RTVE. http://www.rtve.es/noticias/20191111/eleccionesnoviembre-resultados-vox/1989125.shtml

Mateos, A. y Moral, F. (2006). El comportamiento electoral de los jóvenes españoles. Instituto de la Juventud. 
RLCS, Revista Latina de Comunicación Social, 77, 203-229

[Investigación] DOI: 10.4185/RLCS-2020-1455 | ISSN 1138-5820 | Año 2020

Mosse G. L. (1974). The Nazionalization of the Masses. Political Symbolism and Mass Movements in Germany from the Napoleonic Wars through the Third Reich. Howard Fertig.

Mudde, C. (2007). Populist Radical Right Parties in Europe. Cambridge University Press.

Norris, P. (2005). Radical Right: Voters and Parties in the Electoral Market. Cambridge University Press.

Pinazo, D., Nós, E., y Agut, S. (2020). Comunicar en positivo o en negativo en el activismo social. Comunicar, 68(1), 67-76.

Pardo, P. (27 de abril de 2019). Make Spain Great Again. Foreign Policy. https://foreignpolicy.com/2019/04/27/vox-spain-elections-trump-bannon/

Rendueles, L. (9 de marzo de 2019). Vox confía en Bannon para entrar en el Parlamento Europeo. Elperiodico.com https:/www.elperiodico.com/es/internacional/20190309/vox-de-mario-conde-ylos-iranies-a-los-whatsapp-para-maridos-cabreados-7344019

Requeijo, P. (2018). Pablo Iglesias en la Caja Mágica: un análisis retórico. En Rodríguez Torres, J. y Durán Medina, J. F. (Coord.) Propuestas docentes para un nuevo currículum universitario. (pp. 337-350). Tecnos.

Rincón, R. (15 de octubre de 2019). Sentencia del 'procés': penas de 9 a 13 años para Junqueras y los otros líderes por sedición y malversación. El País.

https://elpais.com/politica/2019/10/14/actualidad/1571033446 440448.html

Rogers, E. (1981). Communication Networks. Free Press.

Rokeach, M. (1960). The Open and Closed Mind: Investigations into the Nature of Belief Systems and Personality Systems. Basic Books.

Romero, J. (21 de octubre de 2019). El Gobierno exhumará a Franco del Valle de los Caídos el jueves 24 de octubre a las 10:30. El Confidencial. https://www.elconfidencial.com/espana/2019$\underline{\text { 10-21/gobierno-franco-exhumacion-24-octubre-10-30_2292407/ }}$

Rubio-Pueyo, V. (2019). Vox: ¿Una nueva extrema derecha en España? Nueva York: Fundación Rosa Luxemburg. http://www.rosalux-nyc.org/wp-content/files mf/rubiovox esp final web.pdf

Rydgren, J. (2018). The Oxford Handbook of the Radical Right. Oxford University Press.

Selva-Ruiz, D., y Caro-Castaño, L. (2017). Uso de Instagram como medio de comunicación política por parte de los diputados españoles: la estrategia de humanización en la "vieja" y la "nueva" política. El profesional de la información, 26(5), 903-915.

https://doi.org/10.3145/epi.2017.sep.12

The Social Media Family (2019). Estudio sobre los usuarios de Facebook, Twitter e Instagram en España. https://thesocialmediafamily.com/ 
RLCS, Revista Latina de Comunicación Social, 77, 203-229

[Investigación] DOI: 10.4185/RLCS-2020-1455 | ISSN 1138-5820 | Año 2020

Sheldon, P., y Bryant, K. (2016). Instagram: Motives for its use and relationship to narcissism and contextual age. Computers in Human Behavior, (58), 89-97.

https://www.sciencedirect.com/science/article/abs/pii/S0747563215303307

Valera Ordaz, L., Calvo, D. y López García, G. (2018). Conversaciones políticas en Facebook. Explorando el papel de la homofilia en la argumentación y la interacción comunicativa. Revista Latina de Comunicación Social, (73), 55-73.

http://www.revistalatinacs.org/073paper/1245/04es.html https://doi.org/10.4185/RLCS-2018-1245

Van Dijk, T. A. (2001). Ideología. Gedisa.

Van Dijk, T. A. (2005). Discurso, conocimiento e ideología Reformulación de viejas cuestiones y propuesta de algunas soluciones nuevas. CIC. Cuadernos de Información y Comunicación, (10), 285-318. https://revistas.ucm.es/index.php/CIYC/article/view/CIYC0505110285A

Verdú, D. (25 de marzo de 2019). Steve Bannon, exasesor de Donald Trump y uno de los padres del populismo, explica su relación con Vox y el asalto a Europa del grupo de partidos a los que aconseja. El País. https://elpais.com/internacional/2019/03/24/actualidad/1553454729_290547.html

Viejo, M. (16 de diciembre de 2018). La estrategia de Vox en redes sociales: ya es el primer partido en Instagram, la plataforma con más jóvenes. El País.

https://elpais.com/politica/2018/12/12/actualidad/1544624671_005462.html

Vox (2014). Manifiesto fundacional. https://www.voxespana.es/espana/manifiesto-fundacional-vox

Vox (2015a). Estatutos. https://www.voxespana.es/wp-content/uploads/2016/05/ESTATUTOSVOX-Aprobados-18-10-15.pdf

Vox (2015b). Las 100 medidas de mejora VOX para todos los municipios de España. https://www.voxespana.es/wp-content/uploads/2015/04/100-medidas-mejora-VOX-para-todosmunicipios-de-Espa a-publicaci n1.pdf

Vox (2018). 100 medidas para la España viva. https://www.voxespana.es/noticias/100-medidasurgentes-de-vox-para-espana-20181006

Vox (2019). Estatutos. https://www.voxespana.es/espana/estatutos

Zuckerman, E. (2017). Los gatitos monos al rescate. Redes sociales y participación política. CIC. Cuadernos de Información Y Comunicación, (22), 27-46. https://doi.org/10.5209/CIYC.55966 


\section{AUTORAS:}

\section{Eva Aladro Vico}

Profesora Titular del Departamento de Periodismo y Nuevos Medios en la Facultad de Ciencias de la Información de la Universidad Complutense de Madrid, área de Teoría de la Información desde 1996. Directora de la revista Cuadernos de Información y Comunicación. Directora del Grupo Consolidado de Investigación Estructuras Comunicativas e Interacciones entre los distintos niveles de la Comunicación (940820) de la UCM. Autora de 140 artículos, libros y capítulos académicos en el área de su especialización, y traductora de 50 textos especializados en el mismo campo. Premio a la Excelencia Docente UCM del curso 2015-2016. Entre sus libros, Teoría de la Información y la Comunicación Efectiva, La Información Determinante o Las Diez Leyes de la Teoría de la Información. Profesora Invitada en las Universidades de Frankfurt (Alemania), Melbourne (Australia), Tesalónica (Grecia), Atenas (Grecia), Creta (Grecia), Cagliari (Italia) y Monterrey (México). Portavoz de la Plataforma de Ayuda al Teatro Albéniz, la Plataforma para la Reestructuración en la Universidad Complutense de Madrid, así como es escritora de un blog y de 6 libros de poesía. Últimos proyectos de investigación: 1.- Proyecto Europeo AGLAYA-CM: Estrategias de Innovación en Mitocrítica Cultural. Unión Europea, Fondos Estructurales. 200.000 euros. CO-IP. 2. Módulo Jean Monnet The Role Of Public Service Media In Promoting An Active Citizenship And An Inclusive Dialogue. 586770-Epp-1-2017-1-. 3. Proyecto INNOVA DOCENCIA 2018 Activación de la comunicación política mediante redes sociales. IP. 4. Proyecto Europeo Artivism: artistic practices as instruments for social transformation Modalidad de proyecto: CO-IP. ealadro@ucm.es

Î́ndice H: 17.

Orcid ID: https://orcid.org/0000-0003-1986-8312

Google Scholar: https://scholar.google.com/citations? user=MdVEEs4AAAAJ\&hl=en

ResearchID: https://publons.com/researcher/2394887/eva-eav-aladro/

Scopus: $\underline{\text { https://www.scopus.com/authid/detail.uri?authorId }=56041860100}$

\section{Paula Requeijo Rey}

Profesora Ayudante Doctora del Departamento de Periodismo y Nuevos Medios en la Facultad de Ciencias de la Información de la Universidad Complutense de Madrid. Docente en diversas Unidades y Másters, como UCJC, U. de Lleida Cesnext. Premio a la Excelencia Docente UCM del curso 20182019. Está acreditada como Profesora Contratada Doctora y Profesora de Universidad Privada por la Aneca. Investigadora visitante en la Universidad de California (EEUU) y en la Universidad Nacional Autónoma de México (UNAM). Grupo de investigación consolidado Estructuras Comunicativas e Interacciones en los distintos niveles de la Comunicación Interpersonal de la Universidad Complutense. Ha participado en más de una docena de proyectos de investigación incluyendo 5 europeos y varios I+D. 42 trabajos publicados, indexados en primeras posiciones y editoriales. Últimos proyectos de investigación: 1. Proyecto Europeo AGLAYA-CM: Estrategias de Innovación en Mitocrítica Cultural. Unión Europea, Fondos Estructurales. Cuantía: 200.000 euros. 2. Proyecto de Investigación y Desarrollo (I+D) del Programa Estatal de Fomento de la Investigación Científica y Técnica de Excelencia "Produsage Cultural en las Redes Sociales: Industria, Consumo Popular y Alfabetización Audiovisual de la Juventud Española con Perspectiva de Género", con una financiación de 30.000 euros, 2018-2021. 3. Proyecto Innova-Docencia $n^{\circ} 132$ del Vicerrectorado de Evaluación de Calidad de la Universidad Complutense de Madrid "Activación de la Comunicación Política mediante Redes Sociales". Curso 2018-2019, (fecha de inicio 01/06/2018 - fecha fin 30/06/2019). Universidad Complutense. Dirigido por la Profesora Titular Eva Aladro Vico. 4. Proyecto Europeo Artivism: Artistic Practices for Social Transformation. Comisión Europea, Erasmus Plus. Universidad Complutense, Universidad Nottingham Trent (Inglaterra), Asociación 
RLCS, Revista Latina de Comunicación Social, 77, 203-229

[Investigación] DOI: 10.4185/RLCS-2020-1455 | ISSN 1138-5820 | Año 2020

Élan Interculturel (Francia) y Fundación Artemisszió (Hungría) con una financiación superior a 250.000 euros.

p.requeijo@ucm.es

Índice H: 7

Orcid ID: https://orcid.org/0000-0003-2801-9996

Google Scholar: https://scholar.google.es/citations? user=hZh-1MQAAAAJ\&hl=es 